OPEN ACCESS

Edited by:

Wojciech Golusinski,

Poznan University of Medical

Sciences, Poland

Reviewed by:

Mariana Brait,

Johns Hopkins University,

United States

Carl Christofer Juhlin,

Karolinska Institutet (KI), Sweden

*Correspondence:

Rui Manuel Reis

ruireis.hcb@gmail.com

Specialty section:

This article was submitted to

Head and Neck Cancer,

a section of the journal

Frontiers in Oncology

Received: 20 December 2019

Accepted: 19 June 2020

Published: 28 July 2020

Citation:

Arantes LMRB, Cruvinel-Carloni A

de Carvalho AC, Sorroche BP, Carvalho AL, Scapulatempo-Neto $C$ and Reis RM (2020) TERT Promoter

Mutation C228T Increases Risk for Tumor Recurrence and Death in Head and Neck Cancer Patients.

Front. Oncol. 10:1275.

doi: 10.3389/fonc.2020.01275

\section{TERT Promoter Mutation C228T Increases Risk for Tumor Recurrence and Death in Head and Neck Cancer Patients}

\author{
Lidia Maria Rebolho Batista Arantes ${ }^{1}$, Adriana Cruvinel-Carloni ${ }^{1}$, \\ Ana Carolina de Carvalho ${ }^{1}$, Bruna Pereira Sorroche ${ }^{1}$, André Lopes Carvalho ${ }^{1,2}$, \\ Cristovam Scapulatempo-Neto ${ }^{3,4}$ and Rui Manuel Reis ${ }^{1,5,6 *}$
}

${ }^{1}$ Molecular Oncology Research Center, Barretos Cancer Hospital, Barretos, Brazil, ${ }^{2}$ Department of Head and Neck Surgery, Barretos Cancer Hospital, Barretos, Brazil, ${ }^{3}$ Department of Pathology, Barretos Cancer Hospital, Barretos, Brazil, ${ }^{4}$ Pathology and Molecular Diagnostics Service, Diagnosticos da América-DASA, Barueri, Brazil, ${ }^{5}$ Life and Health Sciences Research Institute (ICVS), Medical School, University of Minho, Braga, Portugal, ${ }^{6}$ ICVS/3B's-PT Government Associate Laboratory, Braga, Guimarães, Portugal

Background: Head and neck squamous cell carcinoma (HNSCC) is usually associated to tobacco and alcohol consumption. Increased telomerase activity has been consistently detected in 80-90\% of malignant tumors, including HNSCC. Mutations within the promoter region of telomerase reverse transcriptase (TERT) that confer enhanced TERT promoter activity have been reported in two major hotspots, designated C228T and C250T.

Objectives: To evaluate TERT promoter mutations C228T and C250T in HNSCC patients from Brazil and correlate with patients' outcome.

Materials and Methods: Formalin-fixed paraffin-embedded tissues were obtained from 88 HNSCC patients and analyzed for TERT promoter mutations C228T and C250T by pyrosequencing.

Results: The overall prevalence of hotspot TERT mutations in HNSCC samples was of $27.3 \%$, with $6.8 \%$ at locus C228T and $20.5 \%$ at C250T. The majority (92\%) of mutated cases were located in oral cavity, mainly at the tongue. We observed that $94.4 \%$ of the patients harboring TERT promoter mutation C250T were alcohol consumers ( $p=0.032$ ) and $66.7 \%$ of the patients harboring TERT promoter mutation C228T were not alcohol consumers $(p=0.035)$. The presence of C228T mutation impacted patient outcome, with a significant decrease in disease-free survival (20.0 vs. $63.0 \%, p=0.017)$ and in overall survival (16.7 vs. $45.1 \%, p=0.017$ ).

Conclusion: This is the first report of a TERT promoter mutations in HNSCC patients from South America. The high prevalence of TERT mutation, as well as its association with poor disease-free survival and overall survival, particular at C228T locus might serve as a prognostic biomarker in HNSCC to help clinicians in the management of treatment.

Keywords: HNSCC, TERT promoter mutations C228T and C250T, prognostic biomarker, disease-free survival, overall survival 


\section{INTRODUCTION}

Approximately 834,860 new cases of head and neck cancer are diagnosed each year in the world that encompasses tumors of the oral cavity, pharynx, and larynx (1). The most common type is squamous cell carcinoma (HNSCC) which accounts for over $90 \%$ of all head and neck cancers (2). Usually associated to tobacco and alcohol consumption (3), over the past decades, human papillomaviruses (HPV) have emerged as an important etiological factor for a subset of HNSCC from the oropharynx $(4,5)$. Despite significant progress in all therapeutic modalities, the 5-year overall survival (OS) rate for HNSCC patients is $\sim 50 \%$ and the main reason for treatment failure is the frequent development of loco-regional recurrences (6).

Most HNSCC treatments are associated with high morbidity and toxicity, where recurrent and metastatic disease is usually incurable, highlighting the need for more effective therapies for these patients (7). No new targeted therapies have been approved for HNSCC for decades, other than cetuximab in 2006, which affords only modest response rates $(10-15 \%)$ as monotherapy $(8,9)$. The landscape of HNSCC explains the limited response rates of targeted therapies, as most tumors have multiple genetic factors of oncogenesis and are constantly evolving when it comes to therapy $(7,10,11)$. In an era of personalized cancer therapy, several investigations are currently examining new biological markers as prognostic and predictive factors in HNSCC (12).

Cancer cells, including HNSCC, are characterized by increased telomerase activity (13). This enzymatic complex is active in $\sim 80-90 \%$ of all cancer types and is responsible for the lengthening of telomeres $(13,14)$. One cancer hallmark is to avoid senescence and unrestricted proliferation, a process called immortalization, and one way to achieve this is by reactivating telomerase in somatic cells $(15,16)$. Telomerase activity has been consistently detected in $80-90 \%$ of malignant tumors (16). Mutations within the promoter region of telomerase reverse transcriptase (TERT) that confer enhanced TERT promoter activity, have been reported in two major hotspots, which are located at -124 and -146 base pairs upstream of the transcriptional start site (also designated C228T and C250T, respectively) (17-19).

TERT promoter mutation has been extensively evaluated in different tumors: thyroid, glioblastoma, urothelial, melanoma, among others (20). Literature reports the use of TERT promoter mutation screening programs in thyroid tumors in order to select patients who would benefit from adjuvant treatment and closer follow-up (21), since many studies related the presence of these mutations with poor prognosis (22-25). Glioblastomas also are reported to present a poor prognosis in patients harboring TERT mutations, which were commonly evaluated in combination with IDH and MGMT methylation (26-29). Urothelial carcinoma $(30,31)$ and melanoma also showed worse prognosis in patients harboring TERT mutation $(32,33)$.

TERT promoter mutations resulting in increased telomerase expression have been detected in a significant proportion of HNSCC patients $(13,18,19,34-39)$. It may vary from 16 to $70 \%$ of all head and neck subsites, being frequently reported as highly mutated in the oral cavity (37-40). Studies evaluating
TERT promoter mutation in head and neck patients were only performed in a few countries (United States, China, India, Taiwan, Italy, and Poland). To date, no studies have evaluated these mutations in the Brazilian population, therefore the aim of the present study was to evaluate the prevalence of TERT promoter mutations in head and neck cancer patients in Brazil and evaluate for associations with outcome.

\section{MATERIALS AND METHODS}

\section{Patient Samples and DNA Isolation}

This retrospective study included formalin-fixed paraffinembedded (FFPE) HNSCC samples from 88 patients surgically treated between 2006 and 2011 at the Department of Head and Neck Surgery of the Barretos Cancer Hospital, Barretos, SP, Brazil. The inclusion criteria were as follows: previously untreated patients with primary HNSCC, submitted to surgery

TABLE 1 | Clinical and pathological data of the patients enrolled in the study.

\begin{tabular}{|c|c|c|}
\hline Variable & Categories & $n(\%)$ \\
\hline \multirow[t]{2}{*}{ Age } & $\leq 60$ years & $54(61.4)$ \\
\hline & $>60$ years & $34(38.6)$ \\
\hline \multirow[t]{2}{*}{ Gender } & Male & $74(84.1)$ \\
\hline & Female & $14(15.9)$ \\
\hline \multirow[t]{2}{*}{ Tobacco use } & Yes & $73(85.9)$ \\
\hline & No & $12(14.1)$ \\
\hline \multirow[t]{2}{*}{ Alcohol use } & Yes & $61(74.4)$ \\
\hline & No & $21(25.6)$ \\
\hline \multirow[t]{6}{*}{ Anatomic site } & Tongue & $35(39.8)$ \\
\hline & Floor of mouth & $19(21.6)$ \\
\hline & Pharynx & $8(9.1)$ \\
\hline & Larynx & $11(12.5)$ \\
\hline & Gingiva & $11(12.5)$ \\
\hline & Hard palate and jugal mucosa & $4(4.5)$ \\
\hline \multirow[t]{2}{*}{$T$} & cT1-cT2 & $27(30.7)$ \\
\hline & cT3-cT4 & $61(69.3)$ \\
\hline \multirow[t]{2}{*}{ N } & cNO & $41(46.6)$ \\
\hline & $\mathrm{cN}+$ & $47(53.4)$ \\
\hline \multirow[t]{2}{*}{ Clinical stage } & I/II & $15(17.0)$ \\
\hline & III/IV & $73(83.0)$ \\
\hline \multirow[t]{2}{*}{ Radiotherapy } & Yes & $71(68.3)$ \\
\hline & No & $33(31.7)$ \\
\hline \multirow[t]{2}{*}{ Chemotherapy } & Yes & $33(33.0)$ \\
\hline & No & $67(67.0)$ \\
\hline \multirow[t]{2}{*}{ Surgical margins } & Negative & 75 (86.2) \\
\hline & Positive & $12(13.8)$ \\
\hline \multirow[t]{3}{*}{ Extranodal extension } & Negative (N0) & $33(46.5)$ \\
\hline & No $(\mathrm{N}+)$ & $15(21.1)$ \\
\hline & Yes (N+) & $23(32.4)$ \\
\hline \multirow[t]{2}{*}{ Perineural invasion } & Yes & $27(36.0)$ \\
\hline & No & $48(64.0)$ \\
\hline \multirow[t]{2}{*}{ Vascular invasion } & Yes & $19(26.8)$ \\
\hline & No & $52(73.2)$ \\
\hline
\end{tabular}


as the first therapeutic modality with curative intent. The use of these samples was approved by the Barretos Cancer Hospital Institutional Review Board. Hematoxylin and eosin sections corresponding to paraffin blocks containing the samples of interest were reviewed by an expert pathologist to confirm the diagnosis and for characterization of the cellular components present in the samples. Scrapings from the region of tissue identified as having at least $80 \%$ of tumor cells were processed using QIAamp DNA FFPE Tissue Kit (Qiagen, Germany). DNA was quantified in the NanoDrop 2000C (Thermo Scientific ${ }^{\mathrm{TM}}$ ) and stored at $-20^{\circ} \mathrm{C}$ until use.

\section{TERT Promoter Mutational Analysis}

A pyrosequencing assay was performed to examine these two TERT promoter mutations. The primer for pyrosequencing was designed immediately upstream of C250T so that these two mutations are analyzed in the same assay by producing a 162 bp amplicon, which contained the sites of C228T and C250T mutations, as previously described (41). Pyrosequencing assays were performed on a PyroMark Q96ID system using PyroMark Gold reagents (Qiagen).

Sanger sequencing was then performed to confirm the results of pyrosequencing. A fragment of the TERT promoter region was amplified by PCR using the primers 5'-AGTGGATTCGCGGGCACAGA-3' and 5' CAGCGCTGCCTGAAACTC-3', resulting in a PCR product of $235 \mathrm{bp}$, which contained the sites of the c.-124 C>T and c.-146 C > T mutations as previously described (26, 42, 43). PCR was performed with initial denaturation at $95^{\circ} \mathrm{C}$ for $15 \mathrm{~min}$, followed by 40 cycles of denaturation at $95^{\circ} \mathrm{C}$ for $30 \mathrm{~s}$, annealing at $64^{\circ} \mathrm{C}$ for $90 \mathrm{~s}$, elongation at $72^{\circ} \mathrm{C}$ for $30 \mathrm{~s}$, and final elongation at $72^{\circ} \mathrm{C}$ for $7 \mathrm{~min}$. The quality of PCR products was confirmed by gel electrophoresis. DNA sequencing of the PCR product was performed using the BigDye Terminator version

A

CCCCTC/TCCGGGTCCCCGGCCCAGCCCCC/TTCCGGG

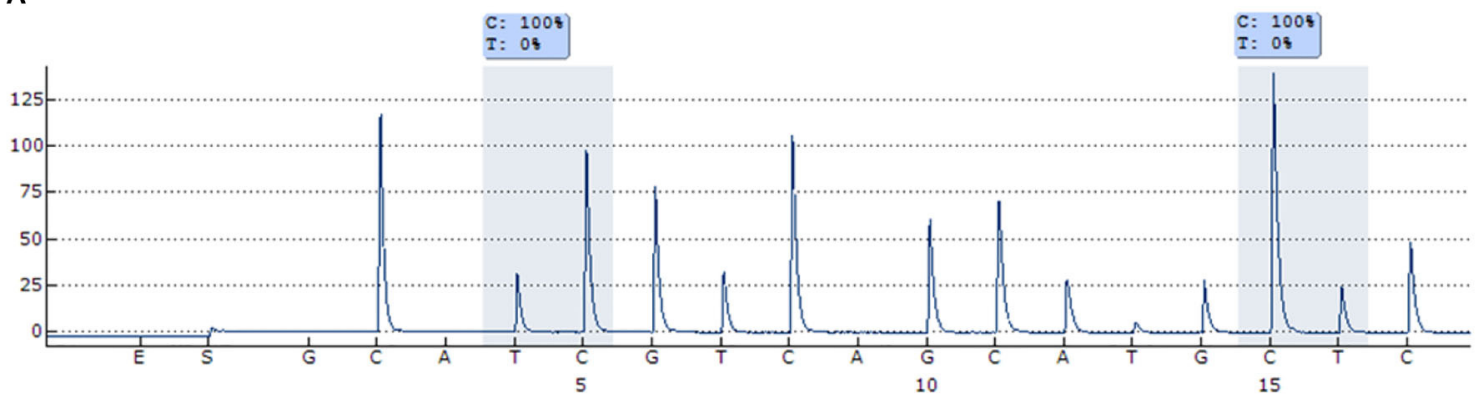

CCCCTC/TCCGGGTCCCCGGCCCAGCCCCC/TTCCGGG

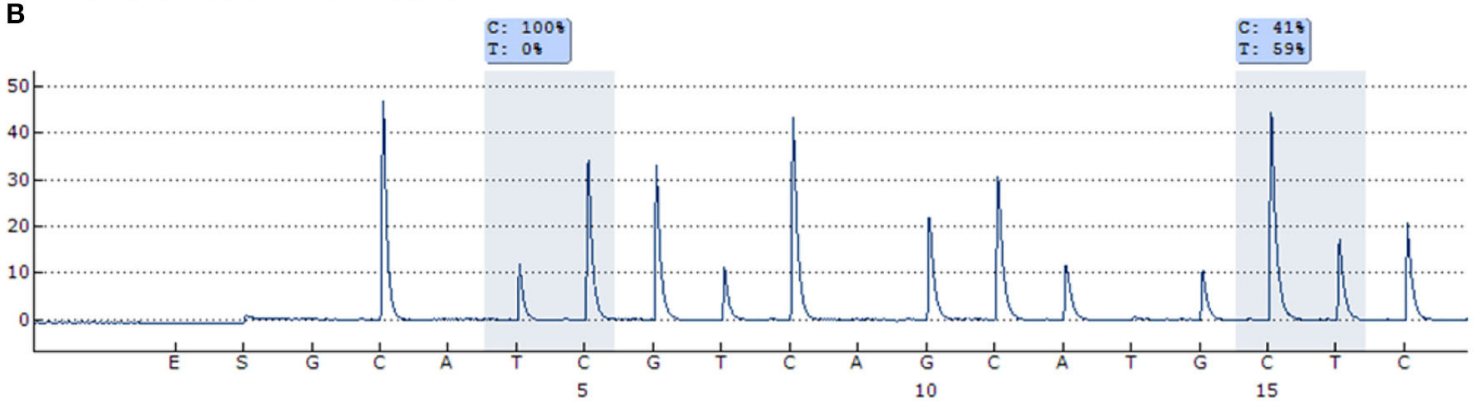

CCCCTC/TCCGGGTCCCCGGCCCAGCCCCC/TTCCGGG

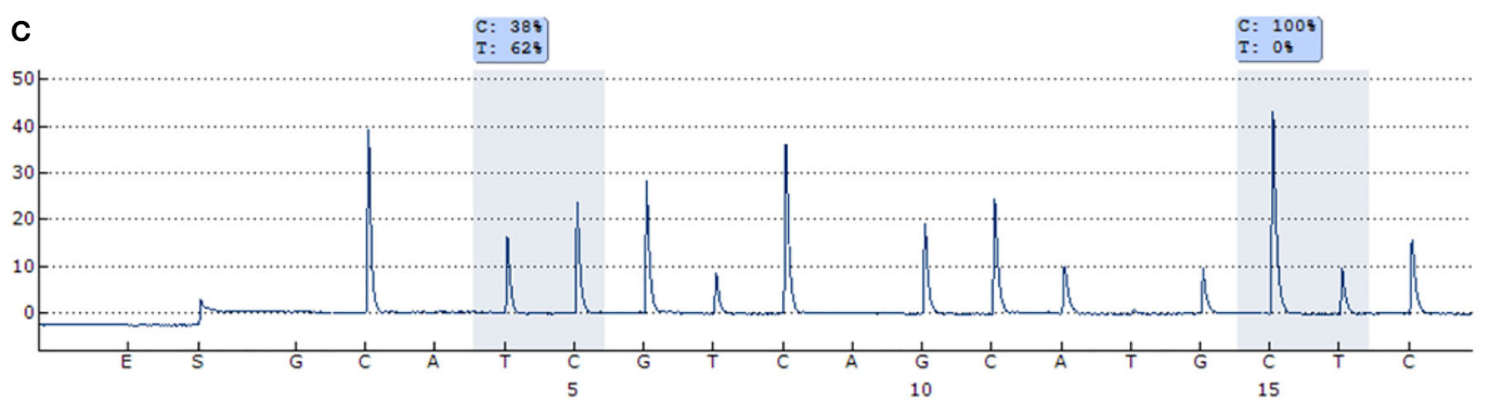

FIGURE 1 | Representative pyrogram of the TERT promoter mutations. (A) Wild-type TERT promoter mutation for C228T and C250T. (B) C228T TERT promoter mutation (59\% of T allele). (C) C250T TERT promoter mutation (62\% of T allele). 
3.1 Cycle Sequencing Kit (Applied Biosystems, USA) and ABI PRISM 3500xL Genetic Analyzer (Applied Biosystems, USA). The sequencing reaction was performed in forward direction. An independent PCR amplification/sequencing, in forward direction, was performed in positive samples or samples that were inconclusive.

\section{Statistical Analysis}

Statistical analysis was performed using the software IBM SPSS Statistics 23 for Windows. Categorical variables were compared using Fisher's exact test. Survival curves were calculated by Kaplan-Meier method and differences between groups were compared using the log-rank test. For all analysis, we considered statistical significance when $p \leq 0.05$.

\section{RESULTS}

\section{Patient Characteristics}

Clinical and histopathological data of the 88 HNSCC patients enrolled in this study are presented in Table 1. Most of the patients profiled in this cohort were male $(84.1 \%)$ with age ranging from 32 to 82 years (median $=58$ years). Tobacco and alcohol consumption were self-reported by 85.9 and $74.4 \%$ of the cases, respectively. Tumor sites were subdivided into oral cavity (78.4\%), larynx (12.5\%), and pharynx (9.1\%). Regarding tumor sub-sites within the oral cavity were as follows: $39.8 \%(35 / 88)$ in the oral tongue, $21.6 \%(19 / 88)$ in the floor of the mouth, $12.5 \%$ $(11 / 88)$ in the gums and $4.5 \%(4 / 88)$ in the hard palate and jugal mucosa. Clinical stage was T1/T2 in 27 cases (30.7\%) and T3/T4 in $61(69.3 \%) ; 47(53.4 \%)$ of the cases had clinically positive cervical lymph nodes and 41 cases $(46.6 \%)$ were N0; collectively, 73 (83.0) had advanced disease at diagnosis. Perineural invasion, vascular invasion, and extranodal extension were present in 27 (36.0\%), 19 (26.8\%), and 23 (32.4\%) cases, respectively (Table 1). It was described a self-reported measure of tobacco and alcohol consumption in three categories: yes, no, and former, which were acquired from the patient's medical records. Analysis was performed considering "yes" vs. "no," where "yes" comprehended smokers or alcohol consumers added to former.

\section{TERT Promoter Mutation in Head and Neck Squamous Cell Carcinoma}

To determine the prevalence of TERT promoter mutations in this cohort of Brazilian patients with HNSCC, genomic DNA was extracted and pyrosequenced. Primers were used to amplify and sequenced a region containing two previously described recurrent TERT promoter mutations (C228T and C250T, Figure 1). The results showed a frequency of $27.3 \%$ $(24 / 88)$ TERT mutations in HNSCC, being $20.5 \%$ at C250T and $6.8 \%$ at $\mathrm{C} 228 \mathrm{~T}$ hotspot regions (Table 2). The mutations occurred in a mutually exclusive manner with a heterozygous genotype. The mutation frequency of $\mathrm{C} 228 \mathrm{~T}$ in tongue was $50.0 \%$, in the gums, hard palate and jugal mucosa and pharynx was $16.67 \%$, while the floor of the mouth and larynx did not present this mutation (Table 2). Regarding C250T mutation, the frequency was $55.56 \%$ for tongue, $33.33 \%$ for the floor of the mouth, 5.56\% for hard palate and jugal mucosa, and for larynx,
TABLE 2 | TERT promoter mutation in HNSCC samples according to tumor sub-sites.

\begin{tabular}{lccc}
\hline Tumor sub-site & C228T $\boldsymbol{n}(\%)$ & C250T $\boldsymbol{n}(\%)$ & WT $\boldsymbol{n}(\%)$ \\
\hline Tongue & $3(50.0)$ & $10(55.56)$ & $22(34.38)$ \\
Floor of the mouth & $0(0.0)$ & $6(33.33)$ & $13(20.13)$ \\
Gums & $1(16.67)$ & $0(0.0)$ & $10(15.63)$ \\
Hard palate and jugal mucosa & $1(16.67)$ & $1(5.56)$ & $2(3.13)$ \\
Larynx & $0(0.0)$ & $1(5.56)$ & $10(15.63)$ \\
Hypopharynx & $1(16.67)$ & $0(0.0)$ & $1(1.56)$ \\
Oropharynx & $0(0.0)$ & $0(0.0)$ & $6(9.37)$ \\
Total & $6(6.8)$ & $18(20.5)$ & $64(72.7)$
\end{tabular}

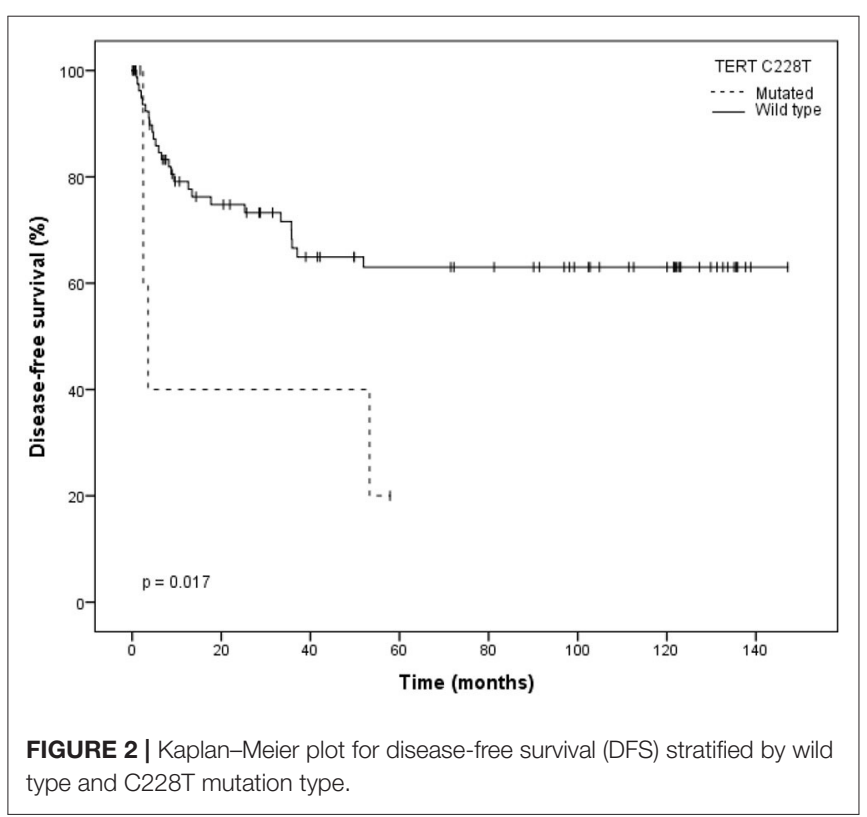

while the gums and the pharynx did not present this mutation (Table 2). When HNSCC sub-sites were grouped in oral cavity, pharynx and larynx, TERT mutations were present in 31.9, 12.5, and $9.1 \%$ of the cases, respectively.

\section{TERT Promoter Mutation Correlation With Clinical and Pathological Features}

In a univariate analysis, $94.4 \%$ of the patients harboring TERT promoter mutation C250T were alcohol consumers $(p=0.032)$. Moreover, $66.7 \%$ of the patients harboring TERT promoter mutation C228T were non-alcohol consumers $(p=0.035)$. When considering cases with either one of the mutations tested, no statistically significant association between the presence of mutation (C228T or C250T vs. wild-type) and clinicalpathological features was observed.

Kaplan-Meier survival curves were used to estimate survival according to TERT promoter mutation status. No statistically significant association between the presence of mutation (C228T or C250T vs. wild-type) and survival was observed. Also, no statistically significant association between the presence of mutation C250T and survival was observed. Importantly, we 
TABLE 3 | Results of univariate analysis of selected prognostic factors for disease-free survival.

\begin{tabular}{|c|c|c|c|c|c|c|}
\hline Characteristics & $\begin{array}{l}\text { Number } \\
\text { of cases }\end{array}$ & $\begin{array}{c}\text { Numberv } \\
\text { of recurrent cases }\end{array}$ & $\begin{array}{c}\text { 5-year disease-free } \\
\text { survival }\end{array}$ & $\begin{array}{c}P \text {-value } \\
\text { (long-rank) }\end{array}$ & $\begin{array}{l}\text { Hazard ratio for } \\
\text { recurrence }(95 \% \mathrm{Cl})\end{array}$ & $\begin{array}{c}P \text {-value } \\
\text { (Cox) }\end{array}$ \\
\hline \multicolumn{7}{|l|}{ Tobacco use } \\
\hline Yes & 73 & 23 & 63.7 & & $0.585(0.238-1.438)$ & \\
\hline \multicolumn{7}{|l|}{ Alcohol use } \\
\hline \multicolumn{7}{|c|}{ Clinical tumor status } \\
\hline T1-T2 & 27 & 10 & 59.8 & 0.811 & Reference & 0.811 \\
\hline Т3-T4 & 61 & 20 & 60.5 & & $1.097(0.513-2.348)$ & \\
\hline \multicolumn{7}{|c|}{ Clinical nodal status } \\
\hline NO & 41 & 10 & 70.8 & 0.040 & Reference & 0.045 \\
\hline \multicolumn{7}{|l|}{ Anatomic site } \\
\hline Oral cavity & 69 & 23 & 61.7 & 0.937 & Reference & 0.937 \\
\hline Pharynx and larynx & 19 & 7 & 52.6 & & $0.967(0.414-2.256)$ & \\
\hline \multicolumn{7}{|l|}{ Surgical margins } \\
\hline Negative & 75 & 22 & 66.0 & 0.038 & Reference & 0.044 \\
\hline Positive & 12 & 7 & 29.1 & & $2.395(1.022-5.612)$ & \\
\hline \multicolumn{7}{|c|}{ Extranodal extension } \\
\hline Negative (NO) & 33 & 6 & 76.8 & 0.31 & Reference & \\
\hline $\mathrm{No}(\mathrm{N}+)$ & 15 & 5 & 61.4 & & $2.093(0.639-6.862)$ & 0.223 \\
\hline Yes $(\mathrm{N}+)$ & 23 & 11 & 41.7 & & $3.560(1.312-9.660)$ & 0.013 \\
\hline No & 82 & 26 & 63.0 & 0.017 & Reference & 0.025 \\
\hline Yes & 6 & 4 & 20.0 & & $3.372(1.169-9.730)$ & \\
\hline \multicolumn{7}{|l|}{ C250T mutation } \\
\hline No & 70 & 24 & 59.6 & 0.992 & Reference & 0.992 \\
\hline Yes & 18 & 6 & 62.8 & & $1.005(0.410-2.461)$ & \\
\hline \multicolumn{7}{|c|}{ C228T or C250T mutation } \\
\hline No & 64 & 20 & 63.3 & 0.250 & Reference & 0.254 \\
\hline Yes & 24 & 10 & 51.2 & & $1.557(0.728-3.331)$ & \\
\hline
\end{tabular}

${ }^{*}$ Clinical stage according to TNM Classification of Malignant Tumors -7 th ed. Bold values indicates the statistical significance ( $\left.p \leq 0.05\right)$.

observed that the 5-year disease-free survival (DFS) for patients harboring mutation $\mathrm{C} 228 \mathrm{~T}$ was 20.0 vs. $63.0 \%$ for patients without this mutation ( $p=0.017$; Figure 2).

Univariate analysis of the effect of this mutation on DFS of patients showed that C228T TERT promoter mutation was significantly associated with an increased risk of tumor relapse $(\mathrm{HR}=3.372$; $95 \%$ CI: $1.17-$ 9.73; $p=0.025 ;$ Table 3). Lower disease-free survival was associated, as expected, with the following clinical characteristics: N-stage (log-rank $p=0.04$ ), extranodal extension (log-rank $p=0.031$ ) and surgical margins (log-rank $p=0.038$; Table 3).

The same negative impact of C228T TERT promoter mutation was observed in the 5-year overall survival (OS) with only $16.7 \%$ of the cases found alive after 5 years, in comparison to $45.1 \%$ of patients without this mutation ( $p=0.017$; Figure 3 ). 
Also, a statistically significant increased risk of death was also observed for the cases harboring this C228T mutation $(\mathrm{HR}=2.708$; 95\% CI: $1.15-6.374 ; p=0.023$; Table 4). A decrease in overall survival was also associated with important clinical factors such as: N-stage (log-rank $p=0.020)$, T-stage (log-rank $p=0.031)$, clinical stage (log-rank $p=0.018)$, surgical margins $(\log -\operatorname{rank} p=0.031)$ and perineural invasion $(\log$-rank $p=0.032$; Table 4).

Finally, a multivariable Cox regression model including alcohol consumption, $\mathrm{N}$-stage, surgical margins and the status of C228T for disease-free survival was performed and, only the status of $\mathrm{C} 228 \mathrm{~T}$ remained significant $(\mathrm{HR}=3.372$; 95\% CI: $1.169-9.730 ; p=0.025)$. In the multivariable Cox regression model including $\mathrm{T}$-stage, $\mathrm{N}$-stage, clinical stage, surgical margins, and the status of C228T for overall survival, clinical stage remained significant $(\mathrm{HR}=2.373$; 95\% CI: $1.072-$ 5.256; $p=0.033$ ) and the status of C228T was marginally significant $(\mathrm{HR}=2.352 ; 95 \% \mathrm{CI}: 0.995-5.558 ; p=0.051)$.

\section{DISCUSSION}

TERT expression is downregulated as a normal cell divides, resulting in telomere shortening and replicative senescence (36, 44). Telomere length is important for cell cycle regulation, cell senescence, and genetic instability regulation (45). In most cancers, TERT expression is reactivated and overexpressed during tumorigenesis leading to replicative immortality $(35,44)$.

TERT promoter mutation has been heavily reported in melanoma, glioma, urothelial, thyroid, hepatocellular, and nonsmall cell lung cancer $(17,19)$. For head and neck tumors, the frequency of those mutations varies significantly among studies (Table 5). These differences could be explained by tumor subsite, sample size, methodological sensitivity, risk factors, and population ethnicity. In our cohort, 27.5 of cases showed TERT promoter mutation, being higher in the C250T than in the C228T locus, 20.5 and $6.8 \%$, respectively. Inversely to those results, when all sites in the head and neck were considered, TERT promoter mutations of C250T and C228T were observed in 2.8 and $14.8 \%$ in Killela et al. (19) study, 0 and $16.6 \%$ in Cheng et al. (35) study and 6.3 and $30.2 \%$ in Morris et al. (39) study, respectively (Table 5). When only the oral cavity is considered, TERT promoter mutations of C250T was also more frequent than C228T in our study, 24.6 and $7.2 \%$, respectively, corroborating to Barczak et al. (13) report of $40.0 \%$ of C250T mutation being in the mouth. Conversely to our results, frequency of C250T and C228T were 9.7 and 22.0\% in Vinothkumar et al. (36) study, 12.9 and $51.7 \%$ in Chang et al. (37) study, 13.3 and 15\% in Annunziata et al. (38) study and 20 and 55\% in Morris et al. (39) study, respectively (Table 5). In Boscolo-Rizzo et al. (40) study, both mutations were evaluated without distinction, showing $83.3 \%$ frequency in oral cavity. For larynx, our results showed $5.5 \%$ of C250T and $0 \%$ of C228T mutation. Similarly, Qu et al. (34) reported $23.8 \%$ frequency for mutation $\mathrm{C} 250 \mathrm{~T}$ and $3.4 \%$ for C228T, which also differs from Morris et al. (39) laryngeal cohort, reported to be $0 \%$ in $\mathrm{C} 250 \mathrm{~T}$ and $14.3 \%$ in C228T (Table 5). Those differences could be explained due to the different proportion of

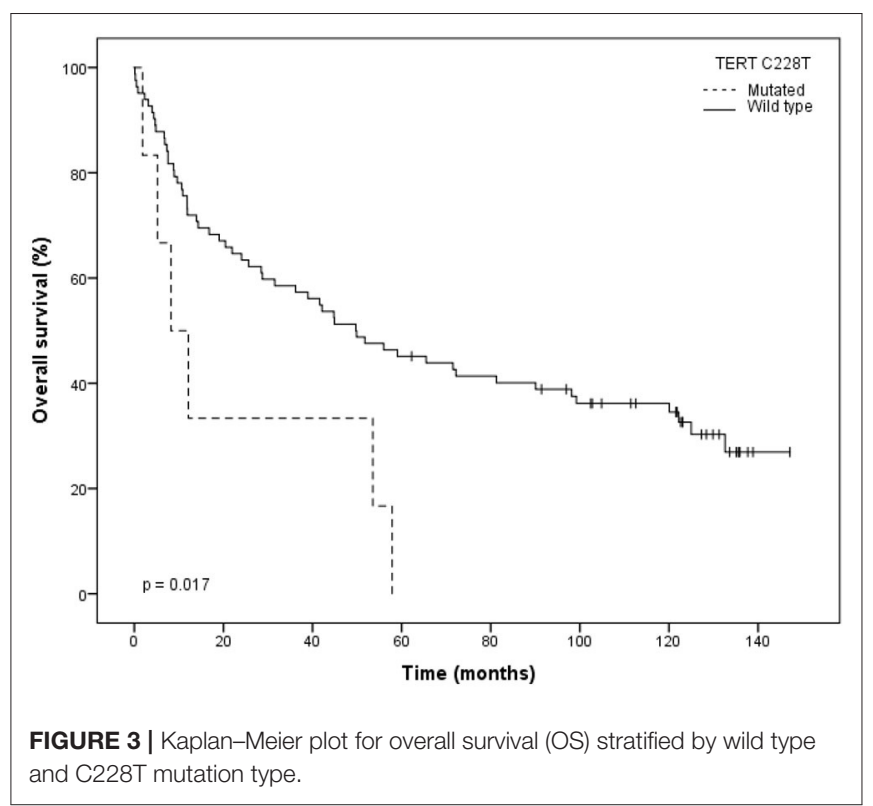

head and neck sub-sites, the number of samples analyzed, and the ethnicity of the patient population (USA, China, India, Taiwan, Poland, and Italy). Brazilian head and neck cancer patients are more likely to be heavy tobacco and alcohol consumers (3) than $\mathrm{HPV}^{+}$(46-48), which can explain the mutagenic effect on the mucosal epithelia of the upper aerodigestive tract. At Barretos Cancer Hospital, we use p16-immunohistochemistry (p16-IHC) as a surrogate marker for HPV infection, as recommended by the 8th edition of AJCC TNM staging system specifically for oropharyngeal squamous cell carcinomas. For the 6 oropharynx SCC evaluated in this study (all WT TERT), p16-IHC was only available for four of them: 1/4 was classified as p16-positive and $3 / 4$ as HPV-negative. Further studies are required in order to assess the correlation between TERT and HPV.

Our data showed a trend in significance with $91.7 \%$ of all mutations occurring in the oral cavity $(p=0.068)$, which was similar to the results reported by Barczak et al. (13) and Killela et al. (19) stating that TERT mutation was correlated to oral cavity, most specifically tongue sub-site.

Interesting, a comparison study evaluating TERT mutation in a head and neck metastatic cohort, the mutation was significantly more frequent in the recurrence then in the primary HNSCC tumors (39). Unfortunately, we did not have the metastatic tumor to compare its mutation profile with the primary tumor in our cohort. Moreover, Chang et al. (37) reported that TERT mutation C228T in oral cavity was also correlated to betel nut chewing, while our study did not find association with tobacco consumption. In contrast, this report found that $94.4 \%$ of the patients harboring TERT promoter mutation C250T were alcohol consumers while $66.7 \%$ of the patients harboring C228T were non-alcohol consumers, in a cohort with $74.4 \%$ of alcohol consumers patients.

Importantly, the present data was able to show the effect of TERT mutation C228T on the 5-year disease-free survival, 
TABLE 4 | Results of univariate analysis of selected prognostic factors for overall survival.

\begin{tabular}{|c|c|c|c|c|c|c|}
\hline Characteristics & $\begin{array}{l}\text { Number } \\
\text { of cases }\end{array}$ & $\begin{array}{l}\text { Number } \\
\text { of deaths }\end{array}$ & $\begin{array}{l}\text { 5-year overall } \\
\text { survival }\end{array}$ & $\begin{array}{c}P \text {-value } \\
\text { (long-rank) }\end{array}$ & $\begin{array}{l}\text { Hazard ratio for } \\
\text { death }(95 \% \mathrm{Cl})\end{array}$ & $\begin{array}{c}P \text {-value } \\
\text { (Cox) }\end{array}$ \\
\hline \multicolumn{7}{|l|}{ Tobacco use } \\
\hline Yes & 73 & 51 & 41.1 & & $1.037(0.492-2.186)$ & \\
\hline \multicolumn{7}{|l|}{ Alcohol use } \\
\hline \multicolumn{7}{|c|}{ Clinical tumor status } \\
\hline T1-T2 & 27 & 16 & 63.0 & 0.031 & Reference & 0.034 \\
\hline Т3-T4 & 61 & 46 & 32.8 & & 1.858 (1.049-3.291) & \\
\hline \multicolumn{7}{|c|}{ Clinical nodal status } \\
\hline No & 41 & 24 & 53.7 & 0.020 & Reference & 0.022 \\
\hline \multicolumn{7}{|l|}{ Anatomic site } \\
\hline Oral cavity & 69 & 48 & 44.9 & 0.905 & Reference & 0.905 \\
\hline Pharynx and larynx & 19 & 14 & 31.6 & & $1.037(0.570-1.886)$ & \\
\hline \multicolumn{7}{|l|}{ Surgical margins } \\
\hline Negative & 75 & 49 & 46.7 & 0.031 & Reference & 0.034 \\
\hline Positive & 12 & 12 & 16.7 & & 2.001 (1.054-3.799) & \\
\hline \multicolumn{7}{|c|}{ Extranodal extension } \\
\hline Negative (NO) & 33 & 20 & 51.5 & 0.202 & Reference & \\
\hline $\mathrm{No}(\mathrm{N}+)$ & 15 & 11 & 33.3 & & $1.380(0.660-2.882)$ & 0.392 \\
\hline Yes $(\mathrm{N}+)$ & 23 & 18 & 30.4 & & $1.777(0.938-3.367)$ & 0.078 \\
\hline \multicolumn{7}{|c|}{ Perineural invasion } \\
\hline No & 82 & 42 & 16.7 & 0.003 & Reference & 0.023 \\
\hline Yes & 6 & 6 & 52.9 & & $2.708(1.150-6.374)$ & \\
\hline \multicolumn{7}{|l|}{ C250T mutation } \\
\hline No & 70 & 40 & 48.1 & 0.606 & Reference & 0.733 \\
\hline Yes & 18 & 8 & 53.6 & & $0.893(0.465-1.715)$ & \\
\hline \multicolumn{7}{|c|}{ C228T or C250T mutation } \\
\hline No & 64 & 45 & 46.9 & 0.445 & Reference & 0.446 \\
\hline Yes & 24 & 17 & 29.2 & & $1.243(0.710-2.177)$ & \\
\hline
\end{tabular}

${ }^{*}$ Clinical stage according to TNM Classification of Malignant Tumors -7 th ed. Bold values indicates the statistical significance $(p \leq 0.05)$.

which was $20.0 \%$ for patients harboring this mutation vs. $63.0 \%$ for patients without this mutation, being therefore associated with an increased risk of tumor relapse. The same negative impact of TERT promoter mutation C228T was observed in the 5 -year overall survival with only $16.7 \%$ of the cases found alive after 5 years, in comparison to $45.1 \%$ of patients without this mutation, also associated with a statistically significant increased risk of death. Corroborating our results, Qu et al. (34) found TERT mutation associated with poor overall survival in laryngeal tumor patients (cases with TERT promoter mutations had 72.2 vs. 78.2 months for wild-type patients, $p=0.04$ ). The mechanism by which TERT promoter mutations ultimately facilitate cancer progression and can constitute prognostic factors are not fully elucidated. It has been reported that $\mathrm{C} 228 \mathrm{~T}$ and C250T mutations are functionally distinct, with C228T leading to GABPA recruitment, whereas C250T generate both an ETS site 
TABLE 5 | Summary of studies evaluating the association between head and neck tumors with TERT promoter mutations.

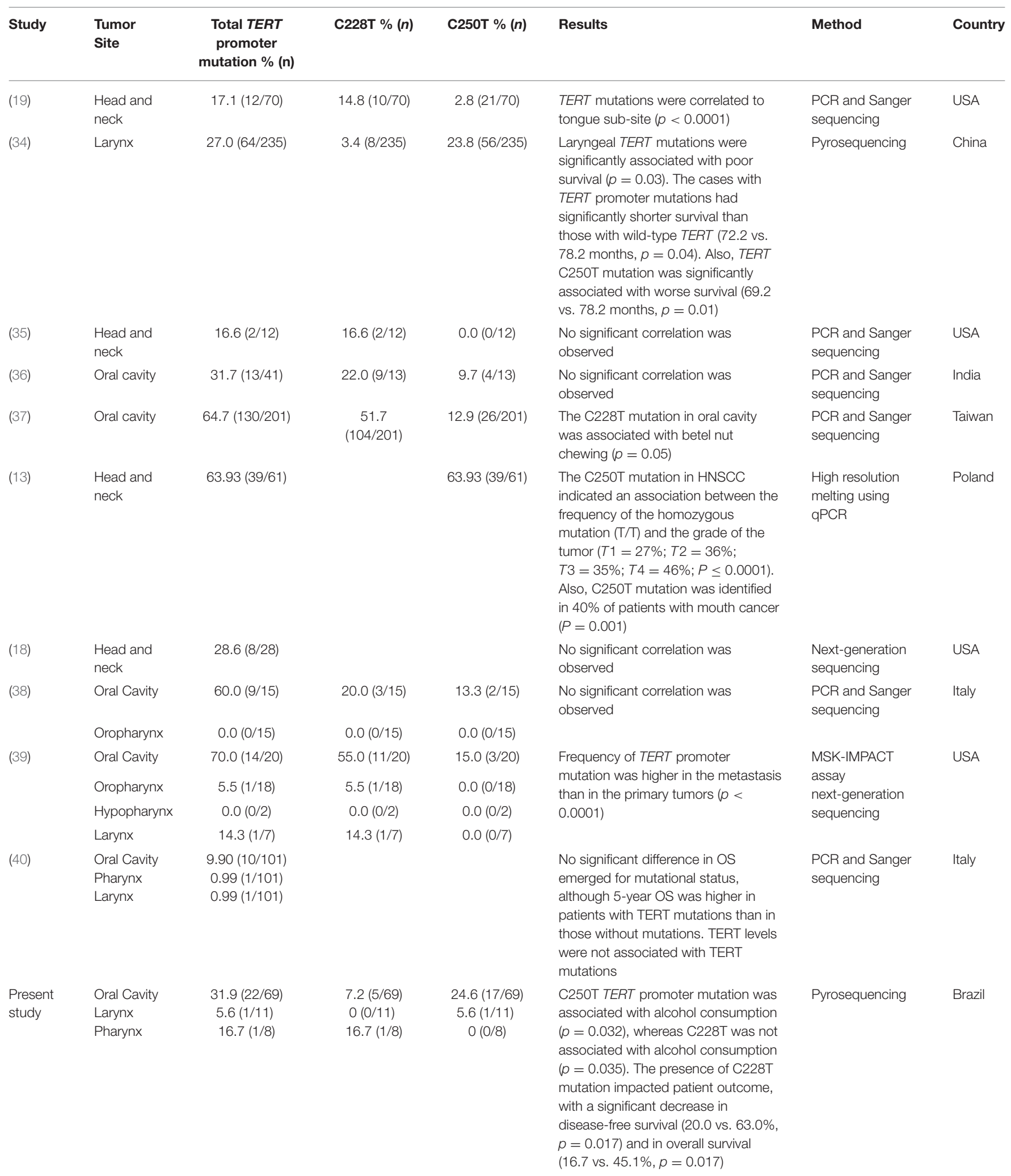


and a functional p52 site requiring ETS1/2 (49). In the present study, we identified only C228T mutations association of worse outcome. This could be due to small size of patients C228T mutated and further studies with a large number should be done to extend and validate this finding.

Chiba et al. (50) recently discovered that TERT promoter mutations may occur in two phases: (1) early stages of tumorigenesis resulting in telomerase activity, which is insufficient to prevent telomere shortening and (2) during subsequent divisions, when the number of short telomeres increases, and telomerase activity becomes rate-limiting, causing telomere-driven genomic instability. Therefore, those mutations promote a dual role in tumorigenesis: cancer cell immortalization and genome instability (50), which seem to be responsible for the increased risk of tumor relapse and increased risk of death in patients harboring the mutation C228T.

Recent studies have reported the feasibility of TERT promoter mutation detection and its applicability in screening programs for patients with thyroid cancer to predict patient's outcome $(21,23)$. Our study suggests that in head and neck tumors, TERT promoter mutations could be performed in a screening setting to help clinicians decide for a more aggressive initial treatment accompanied by a closer follow-up, in order to give these patients a better chance to survive. Studies validating these results should be performed in order to confirm the predictive value of this marker for prognosis. In addition, minimally invasive approaches to detect TERT promoter mutations could be performed in head and neck samples in order to evaluate the feasibility of this marker, and since oral cavity is the most affected site, saliva could possibly be a good source, taking into consideration previous data in other tumors: FNA (Fine-Needle Aspiration) in thyroid tumors (51-53) and cell-free DNA (cfDNA) from urine in urothelial tumors (54-56), which were able to detect the mutation in fluids.

In conclusion, to the best of our knowledge, this is the first study evaluating Brazilian population reporting high prevalence of TERT promoter mutations in HNSCC and associating with poor disease-free survival and overall survival. Thus, TERT promoter mutation $\mathrm{C} 228 \mathrm{~T}$ might serve as a prognostic biomarker in head and neck squamous cell carcinoma to help clinicians in the management of treatment.

\section{REFERENCES}

1. Bray F, Ferlay J, Soerjomataram I, Siegel RL, Torre LA, Jemal A. Global cancer statistics 2018: GLOBOCAN estimates of incidence and mortality worldwide for 36 cancers in 185 countries. CA Cancer J Clin. (2018) 68:394424. doi: $10.3322 /$ caac. 21492

2. Vigneswaran N, Williams MD. Epidemiologic trends in head and neck cancer and aids in diagnosis. Oral Maxillofac Surg Clin North Am. (2014) 26:12341. doi: 10.1016/j.coms.2014.01.001

3. Hashibe M, Brennan P, Chuang SC, Boccia S, Castellsague X, Chen $\mathrm{C}$, et al. Interaction between tobacco and alcohol use and the risk of head and neck cancer: pooled analysis in the International Head and Neck Cancer Epidemiology Consortium. Cancer Epidemiol Biomarkers Prev. (2009) 18:541-50. doi: 10.1158/1055-9965.EPI08-0347

\section{DATA AVAILABILITY STATEMENT}

The datasets generated for this study are available on request to the corresponding author.

\section{ETHICS STATEMENT}

The studies involving human participants and use of these samples were reviewed and approved by the Barretos Cancer Hospital Institutional Review Board. The patients/participants provided their written informed consent to participate in this study.

\section{AUTHOR CONTRIBUTIONS}

RR, CS-N, and ALC designed the study. LA conducted the study, performed the data analysis and interpretation, statistical analysis, and wrote the manuscript. AC-C conducted the study and performed the data analysis. ACC and BS performed the data interpretation and statistical analysis. BS compiled the clinical data. All authors contributed to the article and approved the submitted version.

\section{FUNDING}

This work was supported by the Public Ministry of Labor Campinas (Research, Prevention, and Education of Occupational Cancer, Brazil) and Barretos Cancer Hospital internal research funds.

\section{ACKNOWLEDGMENTS}

The authors would like to thank Natália C. Campanella for her contribution in Sanger sequencing. LA was recipient of scholarship from Fundação de Amparo à Pesquisa do Estado de São Paulo (FAPESP; grant number 2015/12990-0). RR and ALC had a National Counsel of Technological and Scientific Development Scholarship (CNPq). This work was supported by the Public Ministry of Labor Campinas (Research, Prevention and Education of Occupational Cancer, Brazil) and Barretos Cancer Hospital internal research funds.

4. Gillison ML, Koch WM, Capone RB, Spafford M, Westra WH, Wu L, et al. Evidence for a causal association between human papillomavirus and a subset of head and neck cancers. J Natl Cancer Inst. (2000) 92:70920. doi: 10.1093/jnci/92.9.709

5. Gillison ML, D’Souza G, Westra W, Sugar E, Xiao W, Begum S, et al. Distinct risk factor profiles for human papillomavirus type 16-positive and human papillomavirus type 16-negative head and neck cancers. J Natl Cancer Inst. (2008) 100:407-20. doi: 10.1093/jnci/djn025

6. Carvalho AL, Nishimoto IN, Califano JA, Kowalski LP. Trends in incidence and prognosis for head and neck cancer in the United States: a sitespecific analysis of the SEER database. Int J Cancer. (2005) 114:80616. doi: $10.1002 /$ ijc. 20740

7. Mandal R, Senbabaoglu Y, Desrichard A, Havel JJ, Dalin MG, Riaz N, et al. The head and neck cancer immune landscape and its immunotherapeutic implications. JCI Insight. (2016) 1:e89829. doi: 10.1172/jci.insight.89829 
8. Hammerman PS, Hayes DN, Grandis JR. Therapeutic insights from genomic studies of head and neck squamous cell carcinomas. Cancer Discov. (2015) 5:239-44. doi: 10.1158/2159-8290.CD-14-1205

9. Vermorken JB, Trigo J, Hitt R, Koralewski P, Diaz-Rubio E, Rolland F, et al. Open-label, uncontrolled, multicenter phase II study to evaluate the efficacy and toxicity of cetuximab as a single agent in patients with recurrent and/or metastatic squamous cell carcinoma of the head and neck who failed to respond to platinum-based therapy. J Clin Oncol. (2007) 25:21717. doi: $10.1200 / J C O .2006 .06 .7447$

10. Cancer Genome Atlas N. Comprehensive genomic characterization of head and neck squamous cell carcinomas. Nature. (2015) 517:57682. doi: $10.1038 /$ nature 14129

11. Stransky N, Egloff AM, Tward AD, Kostic AD, Cibulskis K, Sivachenko A, et al. The mutational landscape of head and neck squamous cell carcinoma. Science. (2011) 333:1157-60. doi: 10.1126/science.1208130

12. O'Rorke MA, Ellison MV, Murray LJ, Moran M, James J, Anderson LA. Human papillomavirus related head and neck cancer survival: a systematic review and meta-analysis. Oral Oncol. (2012) 48:1191201. doi: 10.1016/j.oraloncology.2012.06.019

13. Barczak W, Suchorska WM, Sobecka A, Bednarowicz K, Machczynski P, Golusinski P, et al. hTERT C250T promoter mutation and telomere length as a molecular markers of cancer progression in patients with head and neck cancer. Mol Med Rep. (2017) 16:441-6. doi: 10.3892/mmr.2017.6590

14. Chen $\mathrm{CH}$, Chen RJ. Prevalence of telomerase activity in human cancer. $J$ Formos Med Assoc. (2011) 110:275-89. doi: 10.1016/S0929-6646(11)60043-0

15. Liu L, Lai S, Andrews LG, Tollefsbol TO. Genetic and epigenetic modulation of telomerase activity in development and disease. Gene. (2004) 340:110. doi: 10.1016/j.gene.2004.06.011

16. Pestana A, Vinagre J, Sobrinho-Simoes M, Soares P. TERT biology and function in cancer: beyond immortalisation. J Mol Endocrinol. (2017) 58:R129-R46. doi: 10.1530/JME-16-0195

17. Vinagre J, Almeida A, Populo H, Batista R, Lyra J, Pinto V, et al. Frequency of TERT promoter mutations in human cancers. Nat Commun. (2013) 4:2185. doi: $10.1038 /$ ncomms 3185

18. Schwaederle M, Krishnamurthy N, Daniels GA, Piccioni DE, Kesari S, Fanta $\mathrm{PT}$, et al. Telomerase reverse transcriptase promoter alterations across cancer types as detected by next-generation sequencing: a clinical and molecular analysis of 423 patients. Cancer. (2018) 124:1288-96. doi: 10.1002/cncr.31175

19. Killela PJ, Reitman ZJ, Jiao Y, Bettegowda C, Agrawal N, Diaz LA Jr, et al. TERT promoter mutations occur frequently in gliomas and a subset of tumors derived from cells with low rates of self-renewal. Proc Natl Acad Sci U S A. (2013) 110:6021-6. doi: 10.1073/pnas.1303607110

20. Gaspar TB, Sa A, Lopes JM, Sobrinho-Simoes M, Soares P, Vinagre J. Telomere maintenance mechanisms in cancer. Genes. (2018) 9:241. doi: 10.3390/genes 9050241

21. Hysek M, Paulsson JO, Jatta K, Shabo I, Stenman A, Höög A, et al. Clinical routine TERT promoter mutational screening of follicular thyroid tumors of uncertain malignant potential (FT-UMPs): a useful predictor of metastatic disease. Cancers. (2019) 11:1443. doi: 10.3390/cancers11101443

22. Bournaud C, Descotes F, Decaussin-Petrucci M, Berthiller J, de la Fouchardiere C, Giraudet AL, et al. TERT promoter mutations identify a high-risk group in metastasis-free advanced thyroid carcinoma. Eur J Cancer. (2019) 108:41-9. doi: 10.1016/j.ejca.2018.12.003

23. Censi S, Barollo S, Grespan E, Watutantrige-Fernando S, Manso J, Iacobone $\mathrm{M}$, et al. Prognostic significance of TERT promoter and BRAF mutations in TIR-4 and TIR-5 thyroid cytology. Eur J Endocrinol. (2019) 181:111. doi: 10.1530/EJE-19-0073

24. Kim TH, Kim YE, Ahn S, Kim JY, Ki CS, Oh YL, et al. TERT promoter mutations and long-term survival in patients with thyroid cancer. Endocr Relat Cancer. (2016) 23:813-23. doi: 10.1530/ERC-16-0219

25. Jin $\mathrm{A}, \mathrm{Xu}$ J, Wang $\mathrm{Y}$. The role of TERT promoter mutations in postoperative and preoperative diagnosis and prognosis in thyroid cancer. Medicine. (2018) 97:e11548. doi: 10.1097/MD.0000000000011548

26. Batista R, Cruvinel-Carloni A, Vinagre J, Peixoto J, Catarino TA, Campanella $\mathrm{NC}$, et al. The prognostic impact of TERT promoter mutations in glioblastomas is modified by the rs 2853669 single nucleotide polymorphism. Int J Cancer. (2016) 139:414-23. doi: 10.1002/ijc.30057
27. Lee Y, Koh J, Kim SI, Won JK, Park CK, Choi SH, et al. The frequency and prognostic effect of TERT promoter mutation in diffuse gliomas. Acta Neuropathol Commun. (2017) 5:62. doi: 10.1186/s40478-017-0465-1

28. Arita H, Yamasaki K, Matsushita Y, Nakamura T, Shimokawa A, Takami H, et al. A combination of TERT promoter mutation and MGMT methylation status predicts clinically relevant subgroups of newly diagnosed glioblastomas. Acta Neuropathol Commun. (2016) 4:79. doi: 10.1186/s40478-016-0351-2

29. Purkait S, Mallick S, Sharma V, Kumar A, Pathak P, Jha P, et al. Prognostic stratification of GBMs using combinatorial assessment of IDH1 mutation, MGMT promoter methylation, and TERT mutation status: experience from a tertiary care center in India. Transl Oncol. (2016) 9:3716. doi: 10.1016/j.tranon.2016.06.005

30. Isharwal S, Audenet F, Drill E, Pietzak EJ, Iyer G, Ostrovnaya I, et al Prognostic value of TERT alterations, mutational and copy number alterations burden in urothelial carcinoma. Eur Urol Focus. (2019) 5:2014. doi: 10.1016/j.euf.2017.07.004

31. Leao R, Lee D, Figueiredo A, Hermanns T, Wild P, Komosa M, et al. Combined genetic and epigenetic alterations of the TERT promoter affect clinical and biological behavior of bladder cancer. Int J Cancer. (2019) 144:1676-84. doi: 10.1002/ijc.31935

32. Andres-Lencina JJ, Rachakonda S, Garcia-Casado Z, Srinivas N, Skorokhod A, Requena $\mathrm{C}$, et al. TERT promoter mutation subtypes and survival in stage I and II melanoma patients. Int J Cancer. (2019) 144:102736. doi: $10.1002 / \mathrm{ijc} .31780$

33. Del Bianco P, Stagni C, Giunco S, Fabozzi A, Elefanti L, Pellegrini S, et al. TERT promoter mutations differently correlate with the clinical outcome of MAPK inhibitor-treated melanoma patients. Cancers. (2020) 12:946. doi: 10.3390/cancers 12040946

34. Qu Y, Dang S, Wu K, Shao Y, Yang Q, Ji M, et al. TERT promoter mutations predict worse survival in laryngeal cancer patients. Int J Cancer. (2014) 135:1008-10. doi: 10.1002/ijc.28728

35. Cheng KA, Kurtis B, Babayeva S, Zhuge J, Tantchou I, Cai D, et al Heterogeneity of TERT promoter mutations status in squamous cell carcinomas of different anatomical sites. Ann Diagn Pathol. (2015) 19:1468. doi: 10.1016/j.anndiagpath.2015.03.005

36. Vinothkumar V, Arunkumar G, Revathidevi S, Arun K, Manikandan M, Rao AK, et al. TERT promoter hot spot mutations are frequent in Indian cervical and oral squamous cell carcinomas. Tumour Biol. (2016) 37:790713. doi: $10.1007 / \mathrm{s} 13277-015-4694-2$

37. Chang KP, Wang CI, Pickering CR, Huang Y, Tsai CN, Tsang NM, et al. Prevalence of promoter mutations in the TERT gene in oral cavity squamous cell carcinoma. Head Neck. (2017) 39:1131-7. doi: 10.1002/hed.24728

38. Annunziata C, Pezzuto F, Greggi S, Ionna F, Losito S, Botti G, et al. Distinct profiles of TERT promoter mutations and telomerase expression in head and neck cancer and cervical carcinoma. Int J Cancer. (2018) 143:115361. doi: 10.1002/ijc.31412

39. Morris LGT, Chandramohan R, West L, Zehir A, Chakravarty D, Pfister DG, et al. The molecular landscape of recurrent and metastatic head and neck cancers: insights from a precision oncology sequencing platform. JAMA Oncol. (2017) 3:244-55. doi: 10.1001/jamaoncol.2016.1790

40. Boscolo-Rizzo P, Giunco S, Rampazzo E, Brutti M, Spinato G, Menegaldo A, et al. TERT promoter hotspot mutations and their relationship with TERT levels and telomere erosion in patients with head and neck squamous cell carcinoma. J Cancer Res Clin Oncol. (2020) 146:3819. doi: 10.1007/s00432-020-03130-z

41. Qu Y, Shi L, Wang D, Zhang B, Yang Q, Ji M, et al. Low frequency of TERT promoter mutations in a large cohort of gallbladder and gastric cancers. Int $J$ Cancer. (2014) 134:2993-4. doi: 10.1002/ijc.28633

42. Campanella NC, Celestino R, Pestana A, Scapulatempo-Neto C, de Oliveira AT, Brito MJ, et al. Low frequency of TERT promoter mutations in gastrointestinal stromal tumors (GISTs). Eur J Hum Genet. (2015) 23:8779. doi: 10.1038/ejhg.2014.195

43. Campanella NC, Penna V, Abrahao-Machado LF, Cruvinel-Carloni A, Ribeiro G, Suehara Y, et al. TERT promoter mutations in soft tissue sarcomas. Int $J$ Biol Markers. (2016) 31:e62-7. doi: 10.5301/jbm.5000168

44. Hanahan D, Weinberg RA. Hallmarks of cancer: the next generation. Cell. (2011) 144:646-74. doi: 10.1016/j.cell.2011.02.013 
45. Deng Y, Chang S. Role of telomeres and telomerase in genomic instability, senescence and cancer. Lab Invest. (2007) 87:10716. doi: 10.1038/labinvest. 3700673

46. Ribeiro KB, Levi JE, Pawlita M, Koifman S, Matos E, Eluf-Neto J, et al. Low human papillomavirus prevalence in head and neck cancer: results from two large case-control studies in high-incidence regions. Int J Epidemiol. (2011) 40:489-502. doi: 10.1093/ije/dyq249

47. Lopez RV, Levi JE, Eluf-Neto J, Koifman RJ, Koifman S, Curado MP, et al. Human papillomavirus (HPV) 16 and the prognosis of head and neck cancer in a geographical region with a low prevalence of HPV infection. Cancer Causes Control. (2014) 25:461-71. doi: 10.1007/s10552-014-0348-8

48. de Carvalho AC, Melendez ME, da Silva Sabato C, Palmero EI, Arantes L, Neto CS, et al. Clinical and molecular characterization of surgically treated oropharynx squamous cell carcinoma samples. Pathol Oncol Res. (2019) 25:1047-58. doi: 10.1007/s12253-018-0462-0

49. Roake CM, Artandi SE. Regulation of human telomerase in homeostasis and disease. Nat Rev Mol Cell Biol. (2020) 21:38497. doi: 10.1038/s41580-020-0234-Z

50. Chiba K, Lorbeer FK, Shain AH, McSwiggen DT, Schruf E, Oh A, et al. Mutations in the promoter of the telomerase gene TERT contribute to tumorigenesis by a two-step mechanism. Science. (2017) 357:141620. doi: 10.1126/science.aao0535

51. Yu FX, Hu MX, Zhao HX, Niu LJ, Rong XY, Li WH, et al. Precise detection of gene mutations in fine-needle aspiration specimens of the papillary thyroid microcarcinoma using next-generation sequencing. Int J Endocrinol. (2019) 2019:4723958. doi: 10.1155/2019/4723958

52. Censi S, Cavedon E, Bertazza L, Galuppini F, Watutantrige-Fernando S, De Lazzari P, et al. Frequency and significance of Ras, Tert promoter, and Braf mutations in cytologically indeterminate thyroid nodules: a monocentric case series at a tertiary-level endocrinology unit. Front Endocrinol. (2017) 8:273. doi: $10.3389 /$ fendo. 2017.00273

53. Liu R, Xing M. Diagnostic and prognostic TERT promoter mutations in thyroid fine-needle aspiration biopsy. Endocr Relat Cancer. (2014) 21:82530. doi: 10.1530/ERC-14-0359

54. Hayashi Y, Fujita K, Matsuzaki K, Matsushita M, Kawamura N, Koh Y, et al Diagnostic potential of TERT promoter and FGFR3 mutations in urinary cellfree DNA in upper tract urothelial carcinoma. Cancer Sci. (2019) 110:17719. doi: 10.1111/cas.14000

55. Avogbe PH, Manel A, Vian E, Durand G, Forey N, Voegele C, et al. Urinary TERT promoter mutations as non-invasive biomarkers for the comprehensive detection of urothelial cancer. EBioMedicine. (2019) 44:4318. doi: 10.1016/j.ebiom.2019.05.004

56. Stasik S, Salomo K, Heberling U, Froehner M, Sommer U, Baretton GB, et al. Evaluation of TERT promoter mutations in urinary cell-free DNA and sediment DNA for detection of bladder cancer. Clin Biochem. (2019) 64:60-3. doi: 10.1016/j.clinbiochem.2018.11.009

Conflict of Interest: The authors declare that the research was conducted in the absence of any commercial or financial relationships that could be construed as a potential conflict of interest.

Copyright (c) 2020 Arantes, Cruvinel-Carloni, de Carvalho, Sorroche, Carvalho, Scapulatempo-Neto and Reis. This is an open-access article distributed under the terms of the Creative Commons Attribution License (CC BY). The use, distribution or reproduction in other forums is permitted, provided the original author(s) and the copyright owner(s) are credited and that the original publication in this journal is cited, in accordance with accepted academic practice. No use, distribution or reproduction is permitted which does not comply with these terms. 